\title{
Para una lectura de El Mago
}

\author{
José Luis Fernández de la Torre
}

Este es el libro con el que, Pedro Molina Temboury obtuvo el Premio Internacional de Poesía Ciudad de Melilla, 1983 . Pero antes de pasar a su análisis se impone una digresión previa: los nuevos poetas, la poesía actual no se identifica con una estética colectiva, se puede afirmar que hay una especie de horror a ser encasillado. Sin embargo, además de la transición, los nuevos poetas están unificados por otros elementos. Por ejemplo, no hay oposición tajante a lo anterior, ni a la poesía de los setenta (novísimos) ni a la de los sesenta (la llamada generación del lenguaje), pero sí se pretende actuar "al margen de". En este sentido la poesía actual es una escritura, un discurso que pretende instalarse en los límites de ese mismo discurso, digamos en los límites de la tradición poética del siglo XX, la inaugurada por, Juan Ramón Jiménez, o los poetas de los años veinte.

A pesar de este esfuerzo continuado la nueva poesía parece sostenerse sobre dos presupuestos ya periclitados: la autonom fa del arte y el interés por el lenguaje o, más propiamente, la búsqueda de la palabra exacta. A veces, incluso, podría pensarse en una cierta incapacidad para centrarse en temas concretos, que se oculta bajo un excesivo "verbalismo". Por eso se reitera que la poesía está en crisis y se recurre a categorías críticas ya caducas: barroquismo, romanticismo, sentimentalismos..., nuevos, eso sí.

Precisamente lo que acabamos de enunciar no es más que otra forma de decir que la nueva poesía intenta ser transgresión, que entre "la realidad y el deseo" la poesía es, sobre todo, reconciliación, al menos, con el yo del poeta. Lo que quiero señalar es que la oposición tradicional razón/sentimiento no es algo natural en poesía, que no se trata de estar a favor de la razón y en contra del sentimiento o a la inversa, sino que, en todo caso, hay que romper con este círculo de asfixia que atenaza a gran parte de la Poesía española actual.

Por todo esto merece destacarse El Mago, en tanto que se separa en cierto modo de esa poesía sensible o sensiblera que es hoy mayoritariamente usada en España.

El Mago, que aparentemente es un libro caótico, resulta ser un poemario unitario aunque esté compuesto por diversas secciones, básicamente tres que podemos denominar: la cotidianeidad (más o menos inmediata), el exotismo hindú y la reflexión puramente poética. 
Posiblemente merezca la pena aclarar que entiendo cotidianeidad en su sentido más amplio, puesto que en el libro oscila desde el rock (dos de los poemas se titulan "Concierto rock") a los astronautas (los titulos aquí son también suficientemente significativos: "Sobre los astronautas muertos en el espacio", "Breve reseña histórica del luna party") y pasa por el pregón de un ciego ("Manifiesto"), o la realidad urbana ("Tema de la noche") o simplemente geográfica ("Monte perdido", "Islas", "Cabo de Trafalgar" ...), o la poetización de la droga como noticia periodística ("Tema del ahogado en Asilah"), o significativamente también la ausencia del amor, o, mejor, la ironización del amor ("Cuidados del amor en el invierno", "El arrancacorazones") y, sobre todo, un culturalismo que se dispersa en la escultura, la pintura o el recuerdo de Miguel Angel ("Florentinos"), etc.

La segunda $-y$ breve - sección, puesto que está formada por ocho poemas, en realidad continúa ese último aspecto cultural que indicaba sólo que centrado en ese mundo exótico de lo oriental que se sucede en poemas-viñetas que muestran la exquisitez de los paisajes ("Lo que le dijo el Ganges a la luna la noche del eclipse", "Lago de Puskhar"), la monumentalidad de su arquitectura ("Los constructores de ciudades", "Taj Mahal") o del urbanismo ("Jaipur") hasta ironizar la presencia colonial inglesa en la India ("Retrato de los marajás, rajás y nababs de la Indica con el virrey inglés").

Inmediatamente hay que añadir que este culturalismo no es una simple referencia iluminadora o un homenaje más o menos exterior, accidental. No, puesto que se integra como sustancia explícitamente discursiva, esto es, las citas, los mitos: Paul Eluard, William Blake, Boris Vian, El escriba del Louvre, los Rolling Stones..., se integran en una explicación sobre la poesía misma.

En consecuencia, podemos observar en $E l$ Mago una diversificación del culturalismo, una disminución de la mitología camp y el vanguardismo disolvente. $Y$ es que en este sentido, estamos ante una poesía intelectualizada aunque no hermética, a pesar de todo en algunas ocasiones aparece la imagen o metáfora sorprendente: "Sobre el diván se estrellan las palabras", "la luna decibélica", el monte es "Un gigante (que) sacude sus espaldas /erizadas de vello/ -el pino, el abedul, las hayas otoñales-", "un beso de plata", "..., la boca de enormes dientes rosas", "una noche sin luna en el desierto / bajo un cielo cuajado de escorpiones", etc.

El Mago se configura así como una visión ejemplificadora del proceso de "creación", con un poema inicial - "El escriba sentado"- y un extenso poema final que da título al libro - "El Mago"- que constituyen un auténtico marco revelador, un arte poética, una declaración de principios sobre la función de la poesía y el poeta. En el primer caso, por ejemplo, podemos leer:

Escriba soy.

Sentado en un museo.

$Y$ entre tanto cadáver ya no encuentro

la tumba del señor a quien debiera 
acompañar al reino de la sombra

-el ha muerto y yo le sobrevivo-.

mientras que en el último poema el escriba-poeta es un "superviviente-alfarero", en realidad, un dios:

Empiezan tus lecciones de Dios padre:

no basta imaginar, has de nombrarlos

si quieres que tus sueños se distingan.

Las criaturas te aguardan,

son tus hijas:

multiplica los monstruos de tu mente, hazlos crecer, morir, reproducirse, dales nombres a todos...

un dios, digamos, nominalista puesto que "cada palabra es un diamante puro", pero a la vez, un dios incompleto porque el "libro-jardín" que produce carece de sentido sin la colaboración del lector. "Yo sueño este poema / tú me sueñas".

De esta manera, Molina Temboury aparentemente puede saltar de un tema a otro: desde su realidad meridional -las playas de Málaga o el cabo de Trafalgar- a Grecia o la India, desde los elementos naturalistas de su "Lección de zoología" a los quásares y naves espaciales. Porque lo que dota de unidad al libro no es esta temática oscilante entre el orientalismo más o menos exquisito y la realidad urbana o moderna más o menos sórdida, sino una cierta propensión metapoética, un continuado esfuerzo por reflexionar sobre la Poesía y el acto creador desde la propia poesía.

El Mago de esta forma deviene en nombre simbólico, en mago de las palabras, el Mago no es más que otra forma de decir Poeta. 